\title{
An Empirical Study on the Science Education Students' Learning Attitude on Science
}

Hongyang Zhang ${ }^{1 *}$, Yue Jia ${ }^{1}$

${ }^{1}$ College of Physics and Information Technology, Shaanxi Normal University, Xi' an 710062, China

*Correspondence: sxtuzhy@qq.com

(Received: 10/11/2019; Accepted: 04/15/2020; Published: 04/21/2020)

DOI: https://doi.org/10.37906/real.2020.2

\begin{abstract}
In China, the five most well-known normal universities have set a special curriculum for a long time, which combines general education and teaching training for education students. In this study, we used the Colorado Learning Attitude about Science Survey (CLASS) to study the learning attitudes on science changes of the education students in the curriculum structure from 8 CLASS dimensions. The results show that: (a) the learning attitudes on science of education students increase with their seniority; (b) in the curriculum structure, the general education has a little effect on improving the learning attitudes on science of the education students, and they gain a lot after teaching training; (c) compared to masters of education, the undergraduates education needs to strengthen in some aspects.
\end{abstract}

Key words: learning attitude, curriculum structure; general education; CLASS.

\section{Introduction}

In the era of information and technology explosion, STEM (Science, Technology, Engineering and Mathematics) education is needed more than ever, due to the importance in fostering innovation among the youth (OECD, 2017) (Graham, Frederick, Byarswinston, Hunter, \& Handelsman, 2013). In particular, science education has particular significance in promoting scientific and technological innovation, talent development and social progress. (Tytler, 2007)

Numerous studies have shown that teachers are one of the main contributors in students' development (Hattie, 2009) (Felder, 1993) (Nay, 2006). It is especially important to training physics teachers, as they play a key role in science education not only because of the fundamental role of physics in science education, but also because of the significant position of physics teachers in students' progress (Rivkin \& Huanushek, 2005). On the one hand, training physics teachers improves their teaching ability; on the other hand, it will develop students' science literacy and foster future innovative talents (Mulhall, 2015).

Nowadays, the five most well-known Chinese normal universities combine general education with teachers' training as the curriculum structure of physics teaching students. In the first two years, these students mostly complete general education courses as the foundation to the degree program, and preparation for a literate life in a modern, global society (Stevenson, Hicks, \& Hubbard, 2016). Physics teacher training courses based on general education began to be more involved in the structure for the last two years, and a number of studies have shown that a single course on physics teaching can create large 
conceptual learning gains, but little work has been done on the whole curriculum structure (Hrepic, et al., 2006) (McDermott, 1991) (Jeness \& Miller, 2005). The curriculum structure focuses on cross-disciplinary integration, the subject of professional education and teacher education, general education and professional education, science education and humanities education integration. The current evaluation system only includes the physics knowledge scores, and ignores the attitude and belief. It is widely acknowledged that physics teachers' learning attitudes and beliefs are as important as their knowledge base, and the attitudes and beliefs are better predictors of science performance (House, College grade outcomes and attrition: an exploratory study of noncognitive variables and academic background as predictors, 1994) (House, Student Motivation, Previous Instructional Experience, and Prior Achievement as Predictors of Performance in College Mathematics, 1995) (Tai, Sadler, \& Mintzes, 2006).

In this paper, we use the Colorado Learning Attitude about Science Survey (CLASS), a survey developed and validated a long time ago and builds on existing surveys, including: the Epistemological Beliefs Assessment for Physical Science(EBAPS) (Elby, Frederiksen, Schwarz, \& White, 1997), the Maryland Physics Expectation Survey(MPEX) (Redish, Sual, \& Steinberg, 1998), and the View about Science Survey(VASS) (Halloun, 1997), to probe the learning attitudes on science of physics teaching students (Adams, et al., 2006; Adams \& Wieman, Development and Validation of Instrument to Measure Learning of Expert-like Thinking, 2011). CLASS, which is suitable for participants at all levels and not tie to specific course, was also designed to distinguishes the beliefs of experts from novices (Adams, et al., 2006) (Semsar, Knight, Birol, \& Smith, 2011) (Allen, Guzman-Alvarez, Uvarov, \& Molinaro, 2016). The statements of CLASS were written as clear and concise as possible (Adams, et al., 2006). Participants need to respond on a Likert scale to 42 statements in 8 dimensions: (1) real world connection, (2) personal interest, (3) sense making/effort, (4) conceptual connections, (5)applied conceptual understanding, (6) problem solving general, (7) problem solving confidence, and (8) problem-solving sophistication (Adams, et al., 2006).

This paper focuses on $S$ normal university as a study example to probe the physics teaching students' learning attitude in different stages on science and analyzed the above-mentioned 8 dimensions. Master of education students have finished the curriculums, and obtain their degrees after two years teaching practicum while working on teaching education in summers. The masters of education students are set as a comparison with the undergraduate students who are enrolling the curriculum structure. This study aims to explore the connection between the curriculum structure and the education students' attitudes and belief $(\mathrm{ABs})$ on science in different dimensions to promote the ABs and improve their teaching abilities.

\section{Methodology}

\subsection{CLASS}

The instrument used in this study is Colorado Learning Attitude about Science Survey (CLASS), because it is suitable for all-leveled students. We used the Mandarin version of CLASS, which was translated by Zhang and Ding for Chinese students. The consistency coefficient $\alpha=0.736$ confirm its reliability (Zhang \& Ding, 2013). The results of the survey were compared with the answers given by the physicists to the scale, and the students' scientific attitudes were evaluated in accordance with the degree (in percentile) (Adams, et al., 2006).

\subsection{Participants and background}

We chose the education students from the College of Physics and Information Technology in S Normal University as participants, and focused on the current situation of their learning attitude on science and fostering issues. In China, students who are attending the same college are usually admitted assuming they have the same level in learning. In order to reduce possible confounding variations, we perform the study 
in the same college. And the masters of education students we chose accepted the same curriculum structure in the same college. They graduated and work for one or two years.

Also, different order and textbooks of the curriculum structure can be the other variations in the study. Since 2006, the S normal university implement the special talent foster program, which combines general education and teaching training for education students. They learn the basic general knowledge and subjects in the first two years. In the other two years, they study the professional course, teaching and practice module. Although there is a little adjustment done on the structure, the main body of the curriculum has changed very little. Figure 1 shows the structure of various courses and the proportion of credits the education students have.

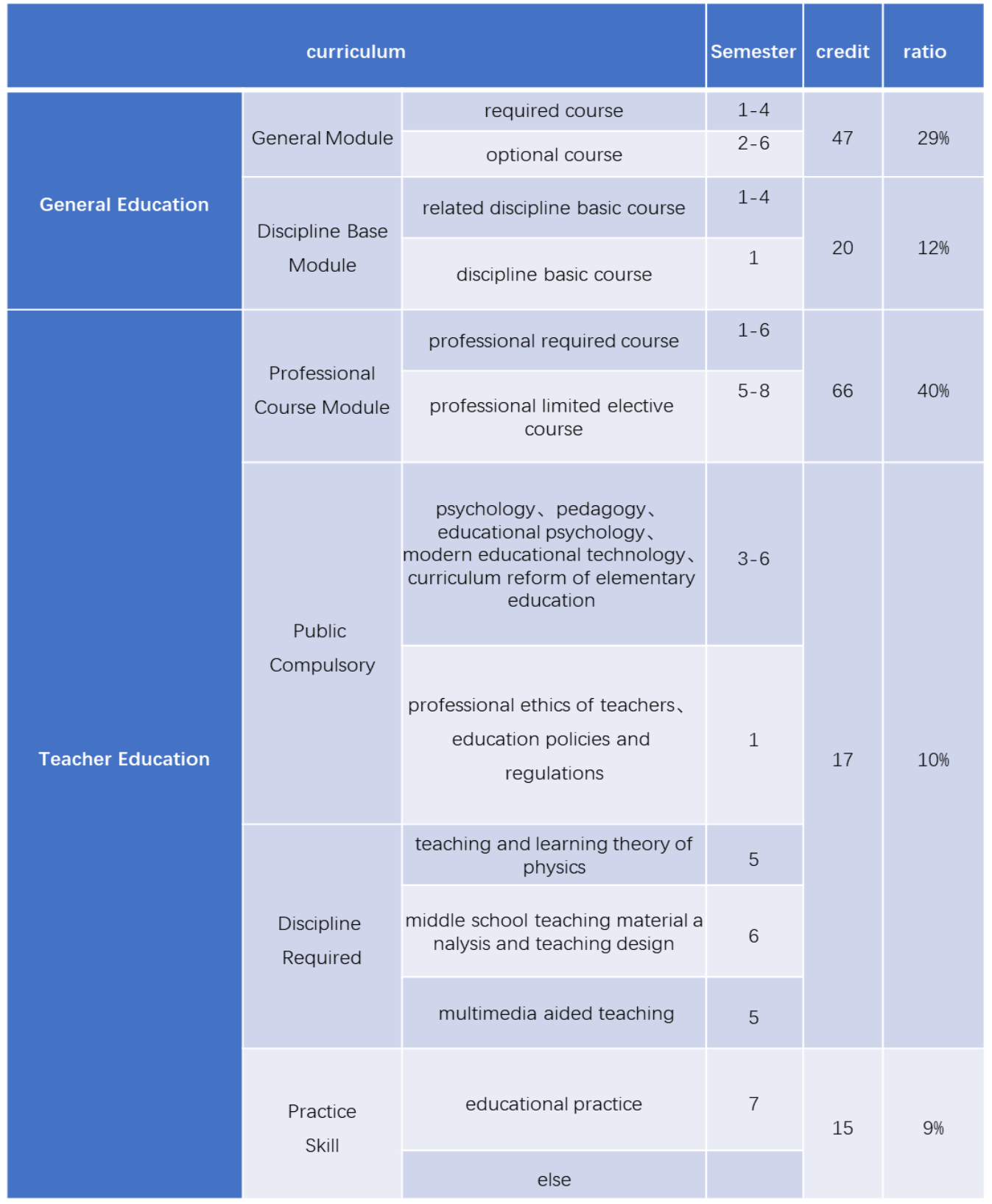

Figure1 Structure of various courses and the proportion of credits 
The survey time of freshman and sophomore students is March 2016, and the junior, senior years is December 2015. The survey of master students is in August 2015, and the data of participants is distributed in Table 1.

Table1 Basic information on the study participants

\begin{tabular}{ccccc}
\hline & Total & \multicolumn{2}{c}{ Gender } & $\begin{array}{c}\text { Effective questionnaire } \\
\text { (percentage) }\end{array}$ \\
\hline Freshman & 119 & Male & Female & 77 \\
\hline Sophomore & 121 & 42 & 79 & $119(95.96 \%)$ \\
\hline Junior & 143 & 45 & 98 & $143(96.80 \%)$ \\
\hline Senior & 95 & 38 & 57 & $95(97.93 \%)$ \\
\hline master of education & 158 & 76 & 82 & $158(96.34)$ \\
\hline
\end{tabular}

\section{Data analysis and results}

3.1. The aggregate results and the development of the learning attitudes on science of the education students

The scores of education students' learning attitudes are generally on rise. In the first two years, the difference is not significant $(\mathrm{t}=1.22, \mathrm{p}<0.05),(\mathrm{t}=3.31, \mathrm{p}<0.05)$. The growth rate is higher than the senior $(t=6.41, p<0.01)$, a most obvious increase. The full data are shown in Table 2 , and we can clearly see each dimension change in different period. 
Table 2 Different stages of free normal school students scientific attitude test results

\begin{tabular}{cccccc}
\hline & Freshman & Sophomore & Junior & Senior & $\begin{array}{c}\text { Master of } \\
\text { Education }\end{array}$ \\
\hline Overall & $52.3 \pm 1.42$ & $53.1 \pm 1.44$ & $54.8 \pm 1.47$ & $61.9 \pm 1.52$ & $73.1 \pm 1.01$ \\
\hline $\begin{array}{c}\text { Personal } \\
\text { Interest }\end{array}$ & $45.21 \pm 1.89$ & $46.78 \pm 2.17$ & $54.80 \pm 2.10$ & $59.98 \pm 2.43$ & $69.43 \pm 1.70$ \\
\hline $\begin{array}{c}\text { Real World } \\
\text { Connection }\end{array}$ & $70.59 \pm 2.51$ & $70.11 \pm 2.77$ & $76.40 \pm 2.44$ & $80.47 \pm 2.54$ & $88.08 \pm 1.57$ \\
\hline $\begin{array}{c}\text { Problem } \\
\text { Solving General }\end{array}$ & $54.98 \pm 1.87$ & $57.94 \pm 1.91$ & $56.70 \pm 1.90$ & $67.67 \pm 2.04$ & $75.66 \pm 1.39$ \\
\hline $\begin{array}{c}\text { Problem } \\
\text { Solving }\end{array}$ & $47.90 \pm 2.43$ & $51.65 \pm 2.43$ & $49.40 \pm 2.22$ & $63.42 \pm 2.56$ & $71.36 \pm 1.67$ \\
Confidence & & & & & \\
\hline $\begin{array}{c}\text { Problem } \\
\text { Solving }\end{array}$ & $39.36 \pm 2.37$ & $38.93 \pm 2.09$ & $41.00 \pm 2.03$ & $48.96 \pm 2.29$ & $65.45 \pm 1.81$ \\
\hline $\begin{array}{c}\text { Sophistication } \\
\text { Sense Making / } \\
\text { Effort }\end{array}$ & $57.82 \pm 1.99$ & $56.79 \pm 2.18$ & $60.40 \pm 2.01$ & $72.88 \pm 2.17$ & $83.07 \pm 1.42$ \\
\hline $\begin{array}{c}\text { Conceptual } \\
\text { Understanding }\end{array}$ & $60.20 \pm 1.96$ & $59.83 \pm 1.92$ & $59.10 \pm 2.24$ & $59.62 \pm 2.28$ & $75.17 \pm 1.50$ \\
\hline $\begin{array}{c}\text { Applied } \\
\text { Conceptual } \\
\text { Understanding }\end{array}$ & $42.72 \pm 2.06$ & $41.42 \pm 1.88$ & $41.90 \pm 2.00$ & $41.99 \pm 2.10$ & $60.71 \pm 1.68$ \\
\hline & & & & \\
\hline
\end{tabular}




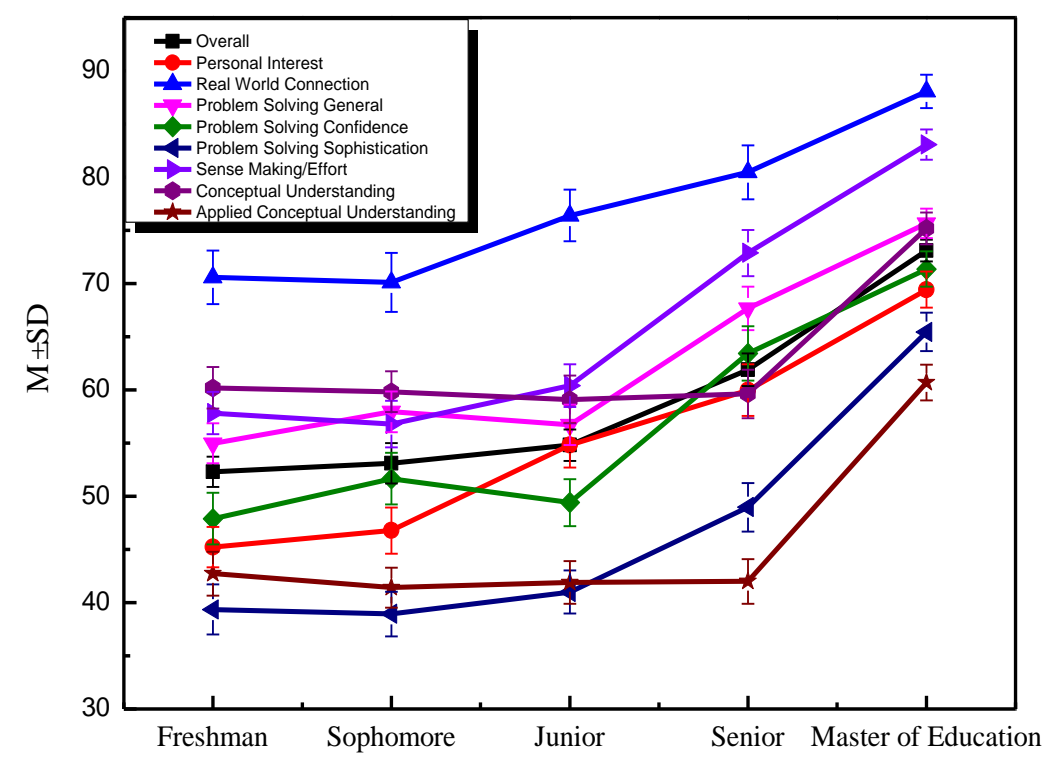

Figure 2 CLASS scores of each dimension comparison

In Figure 2, there is a big difference in the growth speed of state-financed education science students' attitudes in different dimensions. Personal Interest and Real World Connection shows a steady increasing trend. Problem Solving General, Problem Solving Confidence, and Sense Making / Effort increase rapidly from junior year. Problem Solving Sophistication, Conceptual Understanding, and Applied Conceptual Understanding increase rapidly after graduation. The education students CLASS test results of the changes are shown in Figure 2 from freshman to master of education.

3.2. Personal Interest and Real World Connection increase steadily year by year based on the course of the university

With the growth of seniority, the dimensions of Personal Interest and Real World Connection show a stable increasing trend, as shown in Figure 3. The score of Personal Interest is $45.21 \pm 1.89$ in freshman year, and $69.43 \pm 1.70$ in master of education, and the overall performance increases significantly $(t=9.62, p<0.01)$. Real World Connection of the test is $70.59 \pm 2.51$ in the freshman year, and the test scores of the master of education is $70.59 \pm 2.51$, $(\mathrm{T}=5.90, \mathrm{p}<0.01)$, which increased by $-0.67 \%, 8.97 \%, 5.32 \%$ and $9.46 \%$, respectively. The results show that the total score is $88.08 \pm 1.57$. In the CLASS test, Personal Interest and Real World Connection are the two main dimensions that indicate students' level of interest in physics. The close relation among the data above can be seen through the four years of general education in the normal university, the interest of the education students in physics has been improved. Gradually, the relation between physics and real life has been gradually recognized. The test results show a significant change of education students' learning attitudes on science. 


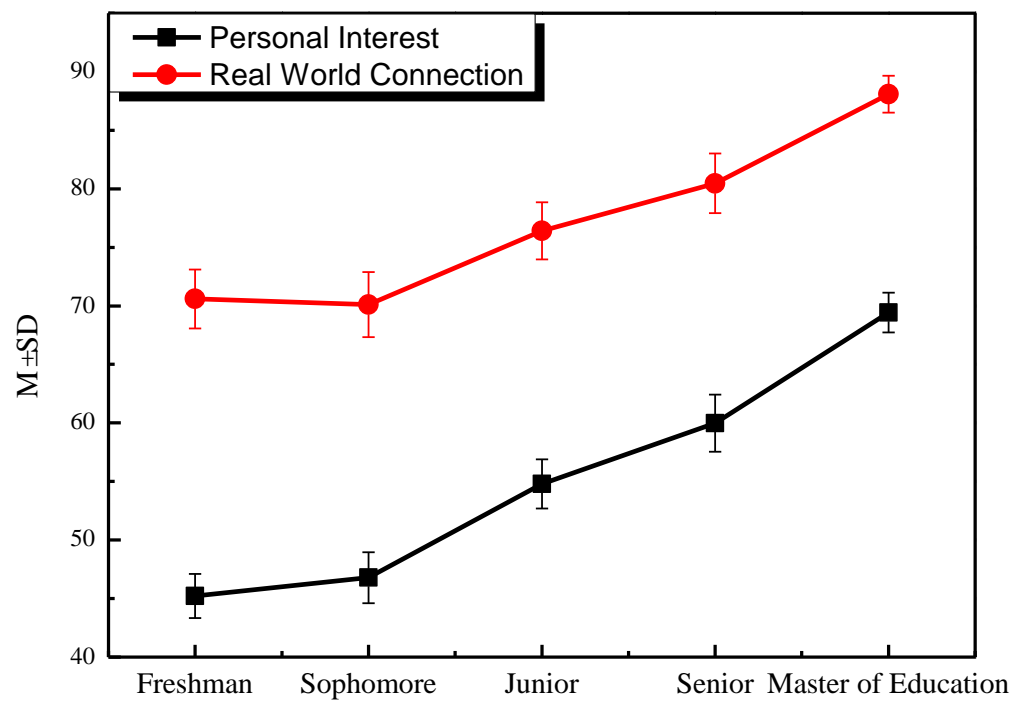

Figure 3 Changes in Personal Interest and Real World Connection

3.3. "Problem Solving General", "Problem Solving Confidence", and "Sense Making/Effort" grow slowly in the first two years of college, and dramatically increase after two years

Figure 4 shows the changes in the performance of education students in the three specific dimensions: Problem Solving General, Problem Solving Confidence and Sense Making/Effort. These three dimensions test scores have not changed much from freshman to junior, which are 2.96, 3.75, and 3.61. Problem Solving General increased by $33.4 \%$, with a significant difference $(\mathrm{t}=8.13, \mathrm{p}<0.01)$, and Problem Solving Confidence increased $44.5 \%$ from the third year to the master of education $(t=7.94, p<0.01)$; Sense Making/Effort increased by $37.53 \%$, and the difference is extremely significant $(t=9.23, p<0.01)$. The increase in two dimensions Problem Solving General, Problem Solving Confidence mainly focus on students solving physics exercises smoothly and flexibly on textbooks. The dimension of Sense Making/Effort indicates students agree with the laws of physics and the efforts experienced by physicists behind the formula, and are willing to invest time and energy in the process of solving physics problems. 


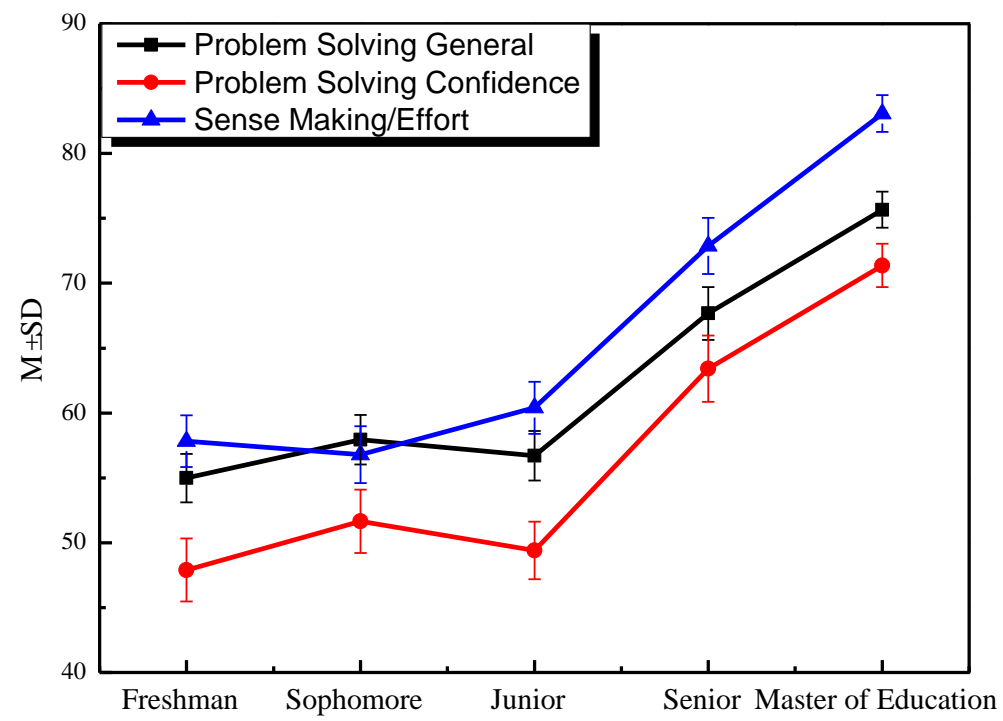

Figure 4 Changes in Problem Solving General, Problem Solving Confidence and Sense Making/Effort

3.4. Problem Solving Sophistication, Conceptual Understanding and Applied Conceptual Understanding change slowly in the four years at university, and grow rapidly after graduation

In the three dimensions of Problem Solving Sophistication, Conceptual Understanding, and Applied Conceptual Understanding, the change in test scores of the four years is small, with Problem Solving Sophistication increasing by 9.6, and Conceptual Understanding decreasing 0.58, the Applied Conceptual Understanding reduced by 0.73 . However, one year after graduation, state-financed education students' test scores have significant changes in the three dimensions of the CLASS. The dimension of Problem Solving Sophistication in master of education (from $48.96 \pm 2.29$ in the senior year) to $65.45 \pm 1.81$ ( $t=7.00$, $\mathrm{p}<0.01)$, and the difference is extremely significant $(t=5.75, p<0.01)$. The Conceptual Understanding increased from $59.62 \pm 2.28$ in the senior year to $74.9 \pm 1.53$, and the difference between them was significant $(\mathrm{t}=5.47, \mathrm{p}<0.01)$. The Applied Conceptual Understanding increased from $41.99 \pm 2.10$ to $60.71 \pm 1.68$ in senior year. Problem Solving Sophistication dimension mainly studies whether students in solving physical problems can use as they learn by analogy. The Conceptual Understanding and Applied Conceptual Understanding dimensions mainly study whether the students truly understood the origin of the physics formulas and the laws. The process of solving problems can be related to the relevance of various knowledge points. The above-mentioned data showed that the education students have become real secondary school teachers after working for a year. They have improved greatly in solving physics problems, understanding and applying physics problems, and changed little in the four years in college. 


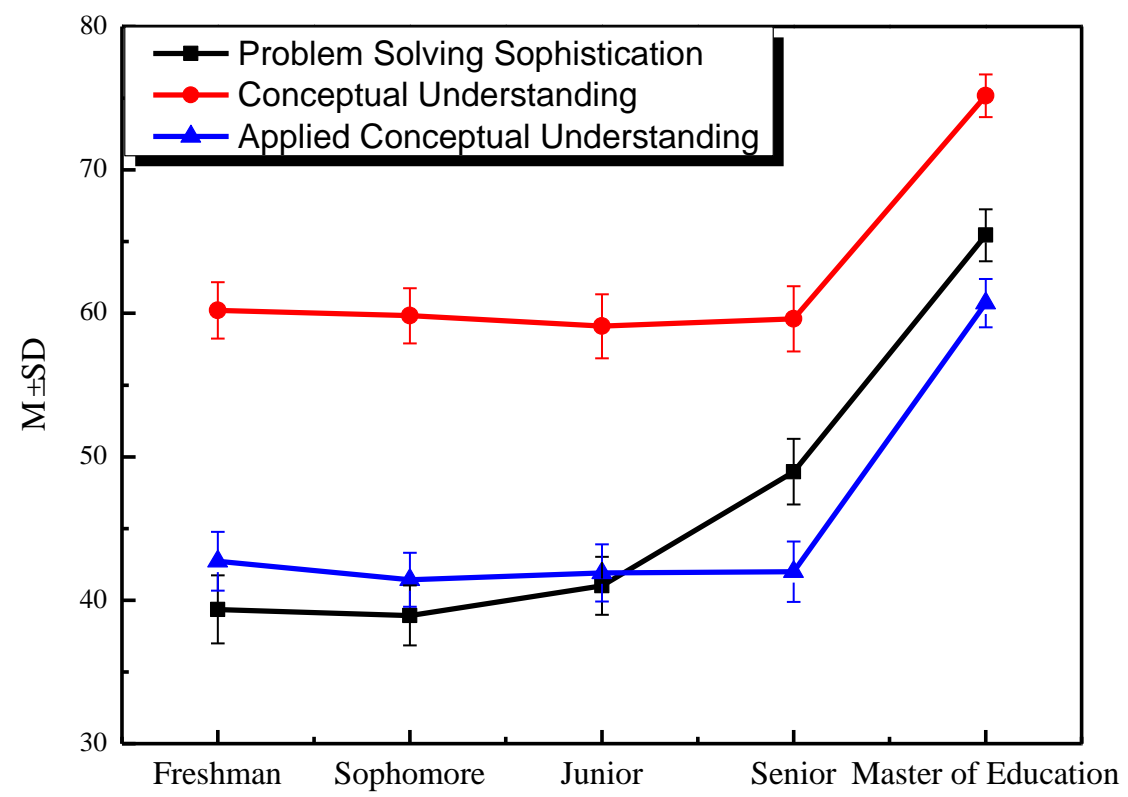

Figure 5 Changes in dimension of Problem Solving Sophistication and Conceptual Understanding and Applied Conceptual Understanding

\section{Discussion}

4.1. The education students in the stage of learning attitudes about science have slow growth in first two years

In the first and second year, the education students mainly took general courses and disciplines of basic courses, and less involved in physics teacher education. The recognition of the curriculum structure is complex. Like the original intention of the curriculum structure setting, the basic knowledge modules of the first two years laid a solid foundation for the subsequent specialized courses, and the common curriculum structure is conducive to student management, helping different university and different professional exchanges. So, there comes a gradually growth. However, the students of the Department of Science in the first two years are lack of the sense of belonging and professional awareness. In result, it is difficult to get an ideal positive shift. In other words, it reflects the possible reasons why in the first two years, the education students' learning attitude about science is in a slow increase.

4.2. State-financed education students' scores in the professional education stage Problem Solving General, Problem Solving Confidence and Sense Making / Effort have significantly improved

Although the first two years of the education students' learning attitudes on science improved little, after entering junior year, students begin to change their scientific attitude, especially in the Problem Solving General, Problem Solving Confidence and Sense Making/ Effort. We randomly interviewed some junior students who participated in the previous survey. The results showed that the courses were very helpful to the students, especially the physics teaching theory, the teaching material analysis, the microteaching and the practical skill training. Firstly, these courses help the students to learn and understand physical knowledge in a higher perspective. Secondly, the teaching practicum in first semester of the fourth year plays a significant role in promoting the scientific attitude. Education and teaching practicum not only students sharpening their skills, but also help them identify their shortcomings and construct a new understanding of student-teacher occupation. 
4.3. In the stage of master of education, the education students' Problem Solving Sophistication, Conceptual Understanding and Applied Conceptual Understanding get a significant progress, but little change during the period of undergraduate

From the school students to secondary school teachers, the role, the point of view, and ideas of thinking of the education students have changed a lot. These changes are mainly reflected in the Problem Solving Sophistication and Conceptual Understanding and Applied Conceptual Understanding. In the student stage, the process of learning physics knowledge is stuck at the level of memorization. However, good teachers will spend more time to understand the concept of physics knowledge, and will do more study of the physics problem in order to make students feel more comfortable in dealing with various problems. When becoming a teacher, they change themselves completely from the recipient of the knowledge to the knowledge transferor. In order to enable students to understand, teachers need to understand the deeper aspects of the concept to tap the background knowledge, context and other knowledge and other connections. Therefore, one or two years after graduation, the education students in problem-solving sophistication and understanding of the application of the concept have a greater improve than the university period.

\section{Conclusions and recommendations}

We used CLASS to assess the education students from the College of Physics and Information Technology in S Normal University. The possible influencing factors of the current curriculum structure results were analyzed from eight dimensions.

In the curriculum structure, the aggregate learning attitudes on science of education students are increasing, especially after teaching training. However, CLASS gains the most in teaching practice and after work. There are still some problems in the curriculum structure. Firstly, there is a long way between the theory and practice of general education in China. The practice of general education does not fully embody the essence of general education concept, and courses can't meet the needs of students. Secondly, we found that the curriculum structure of general education is easy to produce lacking of college belonging, professional consciousness, and CLASS slow promotion. In addition, Problem Solving Sophistication, Conceptual Understanding and Applied Conceptual Understanding dimensions are suffering through a lack of attention.

In view of the above problems, the following recommendations are proposed to the curriculum structure and implementation: (1) Construct the curriculum system of general education scientifically, strengthen the implementation of curriculum, and enhance the teaching effectiveness. Therefore, it is necessary to improve the curriculum of general education, and combine it with teaching training, specifically to create an environment for the effective operation of general education, which requires teachers, school administration and teaching curriculum resources to work together. (2) In the process of teaching, we should pay attention to the cultivation of students' problem-solving ability, the application of the concepts and stimulate interest. While learning, they should be promoted a deep understanding of knowledge in teaching strategies. The teaching process should strengthen interaction between teachers and students from the actual needs of students (knowledge base, cognitive basis, etc.), slow down the progress of teaching, and make the entire teaching philosophy of teaching training throughout the university curriculum and implementation process. (3) In the general education period, we should help students understand the college and professional profiles by professional guidance, extracurricular activities, and research seminars.

The work we have done not only makes sense in the physics education students in S normal university, but also has reference to the setting of curriculum structure and other majors teaching. 
Funding: This research is supported by the Research Program Funds of the Collaborative Innovation Center of Assessment toward Basic Education Quality (NO.2020-05-0036-BZPK01)

Conflicts of Interest: The authors declare no conflict of interest.

\section{References:}

Adams, W. K. , \& Wieman, C. E. . (2011). Development and validation of instruments to measure learning of expert mm ike thinking. International Journal of Science Education, 33(9), 1289-1312.

Adams, W. K. , Perkins, K. K. , Podolefsky, N. S. , Dubson, M. , Finkelstein, N. D. , \& Wieman, C. E. . (2006). New instrument for measuring student beliefs about physics and learning physics: the colorado learning attitudes about science survey. Physical Review Special Topics - Physics Education Research, 2(1), 010101.

Allen, G., Guzman-Alvarez, A., Uvarov, C., \& Molinaro, M. (2016). Revalidation of the Colorado learning attitudes about science survey for chemistry after redefining its categories. Abstracts of Papers of the American Chemical Society, 251.

Elby, A., Frederiksen, J., Schwarz, C., \& White, B. (1997). Epistemological Beliefs Assessment for Physical Science. Retrieved from Proceedings of the American Educational Research Association: http://www2.physics.umd.edu/ elby/EBAPS/home.htm

Felder, R. M. (1993). Reaching the second tier-learning and teaching styles in college science education. , 22(5), 286-290.

Graham, J. M., Frederick, J., Byarswinston, A., Hunter, B. A., \& Handelsman, J. (2013). Science education. incerasing persistence of college students in stem. science, 1455.

Halloun, I. A. (1997). Views about science and physics achievement: the VASS story. The Changing Role of Physics Departments in Modern Universities: Proceedings of theInternational Conference on Undergraduate Physics Education (pp. 605-613). College Park, MD: American Institute of Physics.

Hattie, J. (2009). Visible learning. New York: Routledge.

House, D. J. (1994). College grade outcomes and attrition: an exploratory study of noncognitive variables and academic background as predictors. 60 .

House, D. J. (1995). Student Motivation, Previous Instructional Experience, and Prior Achievement as Predictors of Performance in College Mathematics. International Journal of Instructional Media, 22.

Hrepic, Z., Adams, p., Zeller, J., Talbott, N., Taggart, G., \& Young, L. (2006). In Physics Education Research-2005. AIP Conference Proceeding (pp. 121-124). Melville, NY: American Institute of Physics.

Jeness, M., \& Miller, P. (2005). PET External Evaluation:An Analysis of Pre/Post Content Test Scores. Western Michigan: Mallinson Institute for Science Education.

McDermott, L. C. (1991, 4). Milliken Lecture 1990: What we teach and what is learned-Closing the Gap. Am.J.Phys. 301-315.

Mulhall, P. (2015). Physics teacher education. Encyclopedia of Science Education, 741-743.

Nay, A. M. (2006, 54(1)). Science teaching and the affective attributes of scientists. Science Education, 59-67. 
OECD. (2017). Education at a glance 2017: OECD indicators. Retrieved from Paris: OECD Publishing: https://doi.org/10.1787/eag-2017-en

Redish, E. F., Sual, J. M., \& Steinberg, R. N. (1998). Student expectations in introductory physics. Am.J.Phys, 212-224.

Rivkin, G. S., \& Huanushek, A. E. (2005). Teachers,schools, and academic achievement. Econometrica, $73(2), 417-458$.

Semsar, K., Knight, K. J., Birol, G., \& Smith, K. M. (2011). The colorado learning attitudes about science survey (class) for use in biology. Cbe Life Science Education, 10(3), 268-278.

Stevenson, J., Hicks, S. J., \& Hubbard, A. (2016). Evaluating a general education program in transition. New Directions for Evaluation, 2016(151),37-51.

Tai, R. H., Sadler, P. M., \& Mintzes, J. J. (2006,). Factors Influencing College Science Success. Journal of College Science Teaching, 36(September),52-56.

Tytler, R. (2007). Beyond crsis: remagining science education. teacher the National Education Magazine (October), 40-45.

Zhang, P., \& Ding, L. (2013). Large-scale survey of chinese precollege students' epistemological beliefs about physics: a progression or a regression? . Physical Review Special Topics - Physics Education Research,9(1), 010110. 